\title{
THE USE OF INTERACTIVE WHITEBOARDS IN SOUTH AFRICAN SCHOOLS
}

\author{
Maryke Mihai \\ Department of Science, Mathematics and Technology Education, University of Pretoria (South Africa)
}

\begin{abstract}
The study was aimed at determining the impact of the use of interactive whiteboards (IWBs) in South African classrooms. Interactive whiteboards are one of the technologies which are most commonly used in education worldwide. Technology took over our lives and is becoming more necessary for upcoming generations to become technologically proficient. The Technology Acceptance Model (TAM) was used to determine the perceived ease of use, perceived usefulness and attitudes of educators towards technology. I collected data through short questionnaires from three secondary and five primary schools in Gauteng, where I obtained 122 responses and 18 secondary schools in Mpumalanga, where I received 103 responses. It was determined that more primary school teachers use the IWBs than secondary school teachers in Gauteng and they also use it more effectively. Most of the teachers find the IWBs easy to use and integrate the technology in their lessons. Teachers also indicated that the IWBs are very useful to save their work, to help them to make lessons more interactive, visual and interesting and that the use of the technology motivates learners to participate. The biggest concern is that many teachers still did not receive any training and this is an issue that governing bodies and principals need to address.
\end{abstract}

Keywords: Interactive whiteboards, primary and secondary schools, South African classrooms, Technology Acceptance Model.

\section{Introduction}

One part of the data in this study was obtained from primary and secondary schools in Gauteng, South Africa. These are urban schools. Although interactive whiteboard (IWB) technology is very common worldwide, it is still a resource well utilised in South Africa. I found one primary school and one secondary that were fully equipped with interactive whiteboards. A capital outlay like this reveals the level of commitment of the school governing body.

In rural schools in Mpumalanga, South Africa, a project manager started an IWB network in 2008, when a decision was made that the leading school (LS) would transmit lessons in Science, Mathematics and Maths Literacy to grade 11 and 12 learners in disadvantaged rural schools in the same town. Since then the network expanded to many schools in Mpumalanga. These schools seldom have Science and Maths teachers with a high standard of subject knowledge.

During the transmissions the teachers of the rural schools ensure that the transmissions take place, maintain discipline in their classes and communicate with technicians or the LS if something goes wrong. All the transmissions are done by the HODs and teachers of the LS.

\section{Methods}

This was a qualitative study. Nieuwenhuis in Maree (2007, p. 51) describe qualitative research as research that studies people or systems by interacting with and observing them in their natural environment with the intention of describing and understanding the phenomenon by "looking through the eyes" of the participants, so that the meaning can be described in terms of the meaning that they have for the participants. The emphasis is on the quality and depth of information. 


\section{Design}

Case studies involve systematically gathering enough information about a person, social setting, event or group to permit the researcher to effectively understand how it functions (Berg, 2001). Case study research is descriptive research that involves describing events, conditions, circumstances or situations that are occurring in the present (Thomas, 2010). In this multiple case study, I described the use of the IWBs by the teachers involved.

\section{Participants and data collection}

Five primary schools and three secondary schools in Gauteng, utilising IWBs were chosen. The researcher asked permission from the principals to give questionnaires to the teachers utilising this technology. Thirty questionnaires were obtained from secondary schools and 92 from primary school teachers. In the rural schools, I sent questionnaires to teachers participating in the project in 18 different schools in 12 towns and received 103 responses. In both rural and urban schools, I wanted to determine the ease of use and usefulness of the IWB technology, as well as the attitudes of the teachers. The urban and rural schools filled in the same questionnaires, except that I also posed questions about the management of the network to the rural schools.

\section{Data analysis}

The data was described verbatim. I read the whole data set several times to obtain a whole picture of the teachers' use of and attitudes revealed by the data through the eyes of the participants. I omitted obvious redundancies and repetitions. Thereafter the data was divided in meaning units, parts of the data, communicating sufficient information even if it was read out of context (Elliott \& Timulak, 2005).

\section{Theoretical framework}

The Technology Acceptance Model (TAM) is a model that tries to explain and predict factors of an individual's behaviour towards a new system of technology (Liu, Liao, \& Pratt , 2009). The TAM model's main relevance is that of computer and IT technology (Gong, Xu, \& Yu, 2004). The model is made up of two main beliefs for the use of technology namely; perceived usefulness and perceived ease of use (Liu, Liao, \& Pratt , 2009). Perceived usefulness can be defined as; people may or may not use technology on their belief that it may or may not help improve their job performance (Davis, 1989). Perceived ease of use, according to Davis (1989), even if people believe that the new technology posed to them may be useful it may be too difficult to use and the effort levels outweigh performance benefits.

The Technology Acceptance Model (TAM) proposes a link between the users' perceived usefulness, perceived ease of use, attitude towards technology use, and behavioural intention and actual use of technology. The main idea is that perceived usefulness and perceived ease of use together affect the users' behaviour towards the technology.

Figure 1. Technology Acceptance Model (Davis, 1989).

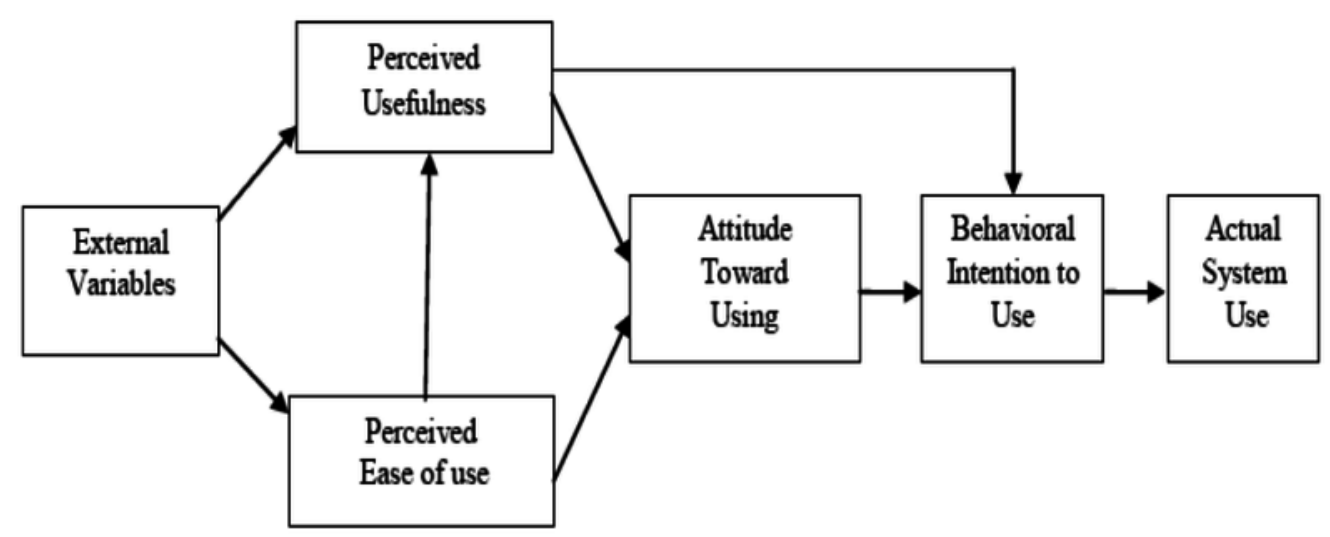


This framework was suitable to this study because it focused on the ease of use of technology, how useful a teacher perceives the IWB technology to be and the attitude of the user. The researcher found that the perceived ease of use, perceived usefulness and attitude had a direct effect on the teaching and learning process.

Oriji and Amadi (2016) also showed in their research that it is necessary for a teacher's attitudes and believes concerning the use of technology in teaching, to change before implementation is possible. They observed that many teachers still fail to see the benefit of using technology and that they believe doing their job in the old way, is still the best way. Teo (2011) stated that teachers need to accept technology before they will implement it and before learners will benefit from it. Studies have found that the success of technology acceptance rely heavily on the attitudes of educators towards technology (Mahat, Jamsandekar and Nalavade, 2012). According to Mahat et al. (2012), “A teacher's attitude or beliefs are one of the several important human factors which have a significant impact on the computer adoption and the implementation of the technology in classroom."

\section{Discussion}

Many teachers find the IWB technology extremely useful and cannot imagine teaching without it. It seems to reduce the workload. A few has comments like "moderate" or just use it as a projector were made. Most find the technology easy to use. Some struggled in the beginning or are still struggling and are merely using the IWB as a whiteboard. Most use the IWB for PowerPoint presentations, videos, mind maps, project worksheets or interactive games.

The main challenges encountered are the calibration of the IWB, the light bulb not working, the Internet being offline, electricity interruptions, the pen that does not work, it is time consuming to set up, updating of the software, the sun shining on the screen and teachers personal lack of knowledge and lack of training.

Visual learning for visual learners is seen as an advantage, as well as the fact that technology is imperative for today's learners. Learners like learning interactively and being entertained. Learners' attention is captured and maintained. From a teacher's perspective, the lessons can be saved to be reused. It is clean and saves time and paper.

Learners' attitudes are generally very positive and they are excited and amazed about the technology. Some seem less involved. The teachers enjoy using it, are excited or just love it. They are eager to learn more.

Most teachers allow the learners to write on the board, do examples of exercises or calculations, play interactive games, use mind maps or do group presentations. Some do not allow learners to use the board at all, because of lack of time or because they are afraid that the learners will scratch the board or break something.

Many teachers think that they had adequate training, but others indicate that it was brief and basic without any follow up. Training is definitely a matter that needs more attention. Although many also indicate adequate support by management, this differs from school to school. Teachers also indicate that they learn most form their fellow educators.

\section{Findings}

Outside transmission time, the IWBs in the rural schools are used for normal classes. Most of the teachers in the rural schools need more training, especially in the use of Maths software, but also in more advanced features of the IWB.

In the urban schools it was found that the primary school teachers utilise the IWBs more than secondary school teachers. Very few secondary schools have IWBs, and if they do, it is usually only in two or three classes. It seems that the primary school learners are also more excited than the secondary school learners about the technology.

In the rural IWB network, only secondary schools are participating and both teachers and learners are very excited about the possibilities of the technology. In the past, learners in the rural schools only had old magazines and text books to use as resources. For them, a new world opened, especially with more career opportunities than ever imagined before.

In the IWB network, the principal and School Governing Body (SGB) of each school is in charge. Their main role is to draw up the budget for the project in each school. The project manager only exists in the LS. His main role at this stage is to obtain more sponsors. He is also responsible for a clear project plan to reach performance targets, determine resource budgets, manage project risks and to sustain a focused and committed team. All the administrative reports in the project are sent to the administrative officer (AO), and mainly the reports of the teachers and HODs. All the results from common tests are sent 
to her before the meetings, so that she can analyse them and determine the improvement or not, and thus she is able to monitor the teachers' progress. She ensures that everybody knows the schedules and gets their calendars and she handles any administrative complaints. The HODs are in charge of their subjects and also ensure that the teachers in the network manage their classes and log in for transmissions and that all administrative issues are sent to the AO.

\section{Conclusion}

Although relatively few schools utilise IWBs in South Africa it is still very well accepted by teachers and learners alike, even though it is still a new practice in schools. It would be beneficial to South African schools to learn from their counterparts in developed countries where the phenomena peaked about 20 years ago. This would give opportunities to make wise investment decisions and to gain insight into possible obstacles before they occur.

\section{References}

Berg, B. L. (2001). Qualitative research methods for the social sciences (4th ed.). USA: Allyn and Bacon.

Davis, F. D. (1989). Perceived Usefulness, Perceived Ease of Use, and User Acceptance of Information Technology. MIS Quarterly, 13, 319-340.

Elliott, R., \& Timulak, L. (2005). Descriptive and interpretive approaches to qualitative research. In J. Miles \& P. Gilbert (Eds.), A handbook of research methods for clinical and health psychology. 147-160. New York: Oxford University Press.

Gong, M., Xu, Y., \& Yu, Y. (2004). An Enhanced Technology Acceptance Model for Web-based Learning. Journal of Information Systems Education, 15, 365-374.

Liu, S.-H., Liao, H.-L., \& Pratt, J. A. (2009). Impact of media richness and flow on e-learning technology acceptance. Computers \& Education, 52, 599-607.

Mahat, S., Jamsandekar, P.P., Nalavade, K. M. (2012). A Study of Teachers Attitudes Towards the ICT Teaching Process. International Journal of Information Technology and Knowledge Management, 6, 93-97.

Nieuwenhuis, F. J. (2007). Introducing qualitative research. In K. Maree (Ed.), First steps in research. 47-68. Pretoria: Van Schaik Publishers.

Oriji, A., \& Amadi, R. (2016). E-education: Changing the Mindsets of Resistant and Saboteur Teachers. Journal of Education and Practice, 7, 122-126.

Teo, T. (2011). Factors influencing teachers' intention to use technology: Model development and test. Computers \& Education, 57, 2432-2440.

Thomas, P. Y. (2010). Descriptive Research. Retrieved December 11, 2018, from http://uir.unisa.ac.za/bitstream/handle/10500/4245/05Chap\%204_Research\%20methodology\%20a nd\%20design.pdf 